University of Nebraska - Lincoln

DigitalCommons@University of Nebraska - Lincoln

\title{
Scintillator Detectors for Scanning Transmission X-ray Microscopes at the Advanced Light Source
}

\author{
S. Fakra \\ Lawrence Berkeley National Laboratory, SFakra@lbl.gov \\ A. L. D. Kilcoyne \\ Lawrence Berkeley National Laboratory, ALKilcoyne@lbl.gov \\ Tolek Tyliszczak \\ Lawrence Berkeley National Laboratory, TTyliszczak@lbl.gov
}

Follow this and additional works at: https://digitalcommons.unl.edu/usdoepub

Part of the Bioresource and Agricultural Engineering Commons

Fakra, S.; Kilcoyne, A. L. D.; and Tyliszczak, Tolek, "Scintillator Detectors for Scanning Transmission X-ray Microscopes at the Advanced Light Source" (2004). US Department of Energy Publications. 322.

https://digitalcommons.unl.edu/usdoepub/322

This Article is brought to you for free and open access by the U.S. Department of Energy at DigitalCommons@University of Nebraska - Lincoln. It has been accepted for inclusion in US Department of Energy Publications by an authorized administrator of DigitalCommons@University of Nebraska - Lincoln. 


\title{
Scintillator Detectors for Scanning Transmission X-ray Microscopes at the Advanced Light Source
}

\author{
S. Fakra*, A.L.D. Kilcoyne ${ }^{\dagger, *}$ and T. Tyliszczak ${ }^{*}$ \\ *Lawrence Berkeley National Laboratory, Berkeley, CA 94720, USA \\ 'Department of Physics, North Carolina State University, Raleigh, NC 27695
}

\begin{abstract}
The choice of x-ray detectors presents a challenge for scanning transmission x-ray microscopes (STXM). The ultimate detector for the ALS STXMs should have a very high efficiency over a wide energy range, single photon counting capabilities up to $1 \mathrm{GHz}$, high rejection of red laser light, fast response, and work in both vacuum and at atmospheric pressure. The results of an investigation using a photomultiplier tube (PMT) with a number of different scintillators are presented. The PMT is used in photon counting and analog modes. Scintillators used for this study include commercially available phosphor powders and various single crystals.
\end{abstract}

\section{INTRODUCTION}

Scanning transmission $\mathrm{x}$-ray microscopes working at soft $\mathrm{x}$-ray energies present a challenge for the choice of $\mathrm{x}$-ray detectors. At the Advanced Light Source, home of the MES 11.0.2 and Polymer 5.3.2 STXMs [1], there is an ongoing quest for better detectors. Higher detection efficiency is crucial as it allows faster data acquisition or to work at higher spectral resolution. It also reduces radiation damage often observed on organic samples. On the Polymer 5.3.2 STXM, radiation damage on polymers and organic samples and lower flux (bending magnet beamline) requires efficient detection. On the MES 11.0.2 STXM, preventing damage on biological and environmental samples due to the very high flux also requires fast and efficient detection.

The ultimate detector for the ALS STXMs should have a very high efficiency over a wide energy range, typically from $150 \mathrm{eV}$ up to $2000 \mathrm{eV}$, single photon counting up to $1 \mathrm{GHz}$, high rejection of parasitic visible light (scattered laser light from the interferometer), fast response, and work in both vacuum and atmospheric pressure.

\section{EXPERIMENTAL DETAIL}

The working principle for scanning transmission $\mathrm{x}$-ray microscopy is relatively simple. X-rays are focused onto a sample by a zone plate lens to about $40 \mathrm{~nm}$, the sample is raster-scanned in the focal plane and the transmitted photons are detected by a stationary detector. An order sorting aperture (OSA) reduces the diffracted beam to the desired diffracted order (usually $1^{\text {st }}$ ).

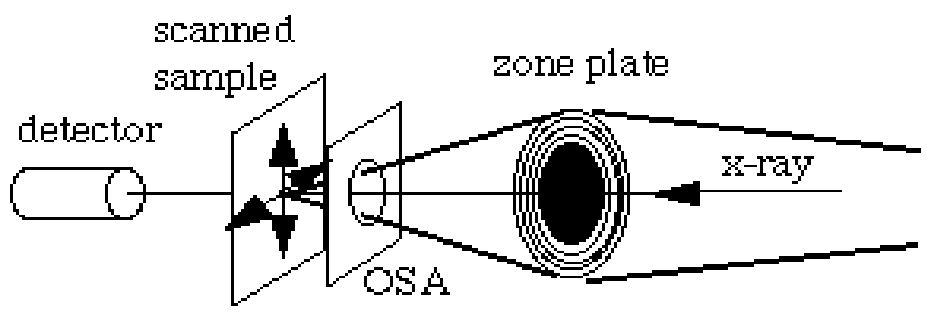

Figure.1. Schematic diagram of a scanning transmission $\mathrm{x}$-ray microscope

The main type of detectors used at both ALS scanning microscopes is a scintillator - light pipe - photomultiplier tube assembly. The inorganic scintillator presently used is a phosphor that converts $\mathrm{x}$-rays into visible light. A lucite 
light-pipe conveys visible photons onto the PMT (Fig.2.). The visible photons are counted using a photon counting unit with count rate capability in the tens of MHz. The PMT is also used in analog mode. The relatively long light pipe is used for two reasons. First, the detector has to fit in the piezo scanning stage frame to allow large scanning range. Second, the PMT has to be far away from the sample in order to reduce the influence of the magnetic field created by a magnet used for sample magnetization measurements. The x-ray beam size is about $0.2 \mathrm{~mm}$ to $0.4 \mathrm{~mm}$ in diameter at the detector position. Two different light pipe tip shapes are used; flat tip for use with single crystal scintillators and a conical tip with a $1 \mathrm{~mm}$ flat top when a phosphor powder is used.

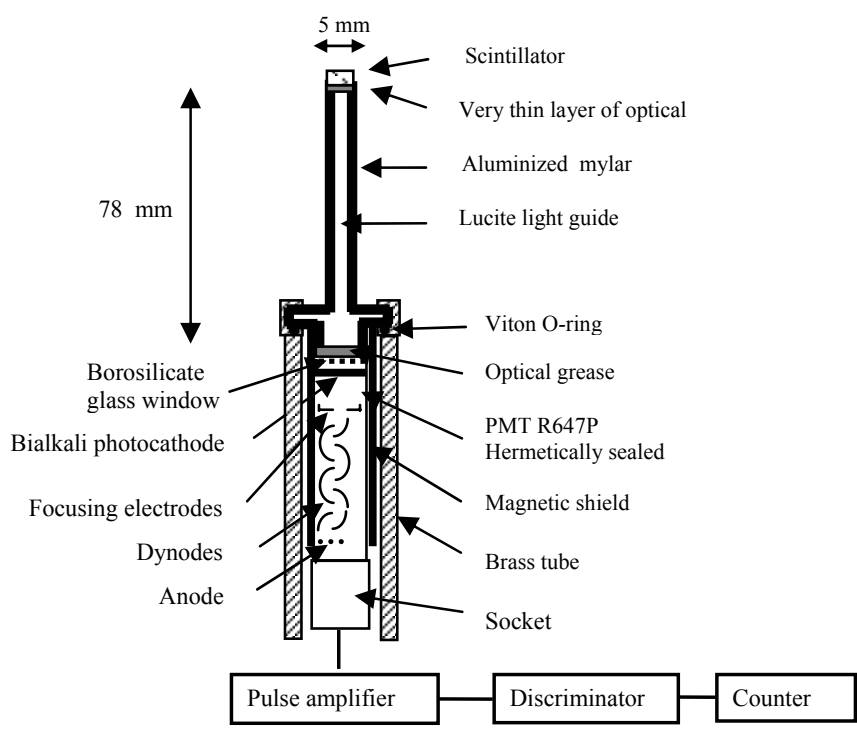

Figure 2. STXM photomultiplier tube detector configuration.

The usefulness of this detector depends upon the properties of the scintillator chosen for the STXM detector. Three single crystal scintillators and three powder phosphors were compared (Table 1). The large scanning area (up to $25 \times 4 \mathrm{~mm}$ ) of the STXM offered unique possibilities to compare those scintillators. The scintillator were mounted on a very thin glass slide $(200 \mu \mathrm{m}$ thick) and scanned in the focused $\mathrm{x}$-ray beam while the luminescent photons were detected with a PMT detector without a scintillator. The angular acceptance angle for the visual photons was kept constant for all scintillators. The exposure time was $1 \mathrm{~ms}$ per pixel unless otherwise noted.

\begin{tabular}{|l||l|c||c|}
\hline Type & Composition & $\begin{array}{c}\text { Wavelength of } \\
\text { maximum emission }\end{array}$ & Decay time \\
\hline P47 & $\mathrm{Y}_{2} \mathrm{SiO}_{5}: \mathrm{Ce}$ & $400 \mathrm{~nm}$ (blue) & $55 \mathrm{~ns}$ \\
\hline P43 & $\mathrm{Gd}_{2} \mathrm{O}_{2} \mathrm{~S}: \mathrm{Tb}$ & $545 \mathrm{~nm}$ (green) & $1 \mathrm{~ms}$ \\
\hline \hline YAP:Ce & $\mathrm{YAlO}_{3}: \mathrm{Ce}$ & $370 \mathrm{~nm}$ (blue) & $27 \mathrm{~ns}$ \\
\hline \hline YAG:Ce & $\mathrm{Y}_{3} \mathrm{Al}_{5} \mathrm{O}_{12}: \mathrm{Ce}$ & 550 (green) & $70 \mathrm{~ns}$ \\
\hline \hline CWO & $\mathrm{CdWO}_{4}$ & $470 \mathrm{~nm}$ (blue) & $28 \mathrm{us}$ \\
\hline
\end{tabular}

Table 1. Scintillators used in this work [2].

\section{RESULTS}

Figure 3a shows an image of 3 different single crystal scintillators obtained at $700 \mathrm{eV}$. One can clearly see that the YAG crystal is more efficient than the YAP and CWO crystals. There is also evidence, that the single crystals do not emit homogeneously. The visual light microscope inspection showed that the spots with higher luminescent emission had a higher quality polished surface. Figure $3 \mathrm{~b}$ shows relative luminescence from those three scintillators as a function of the $\mathrm{x}$-ray energy. 

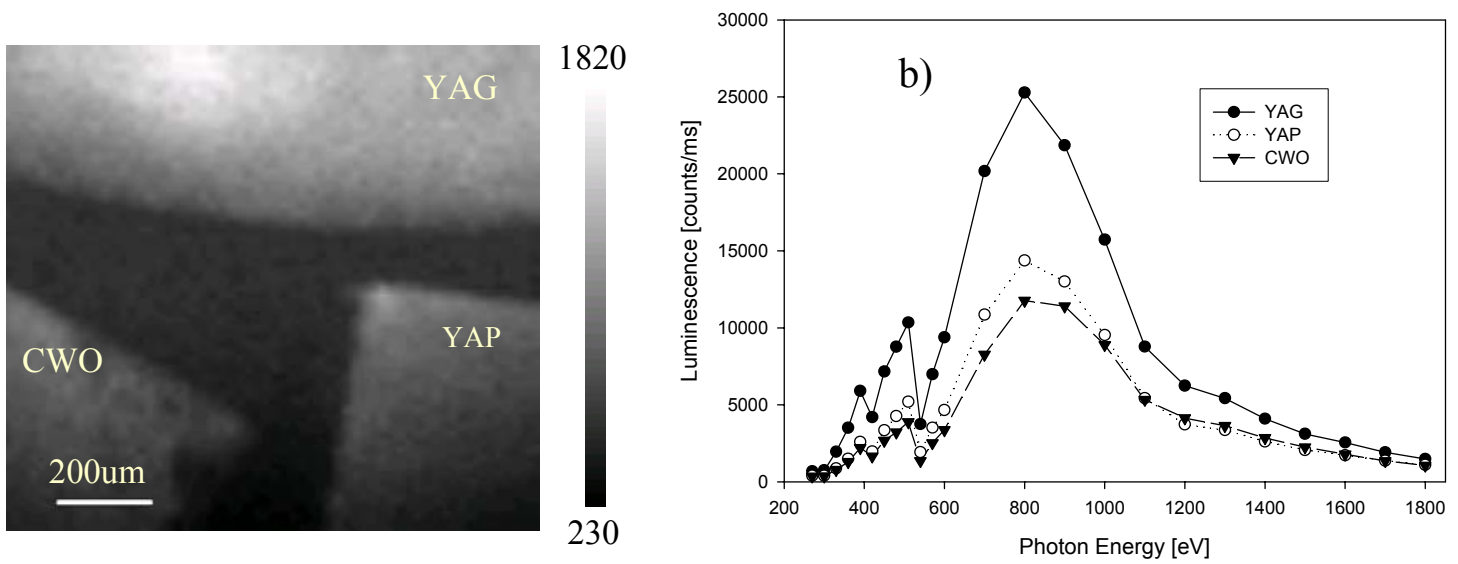

Figure 3. (a) Luminescence image of YAG, YAP and CWO scintillating single crystals recorded at $700 \mathrm{eV}$. (b) Relative luminescence intensity as a function of $\mathrm{X}$-ray photon energy.

Figure 4a shows luminescent images of different phosphor powders. The P47 has significantly higher luminescence then the others. Quantitative comparison has to account for the fact that the P47 powder grains are relatively sparsely distributed and cover only a small percentage of the area. Using only single grain comparison of the energy dependence of the luminescence (Figure 4b), the significance of this problem was reduced.
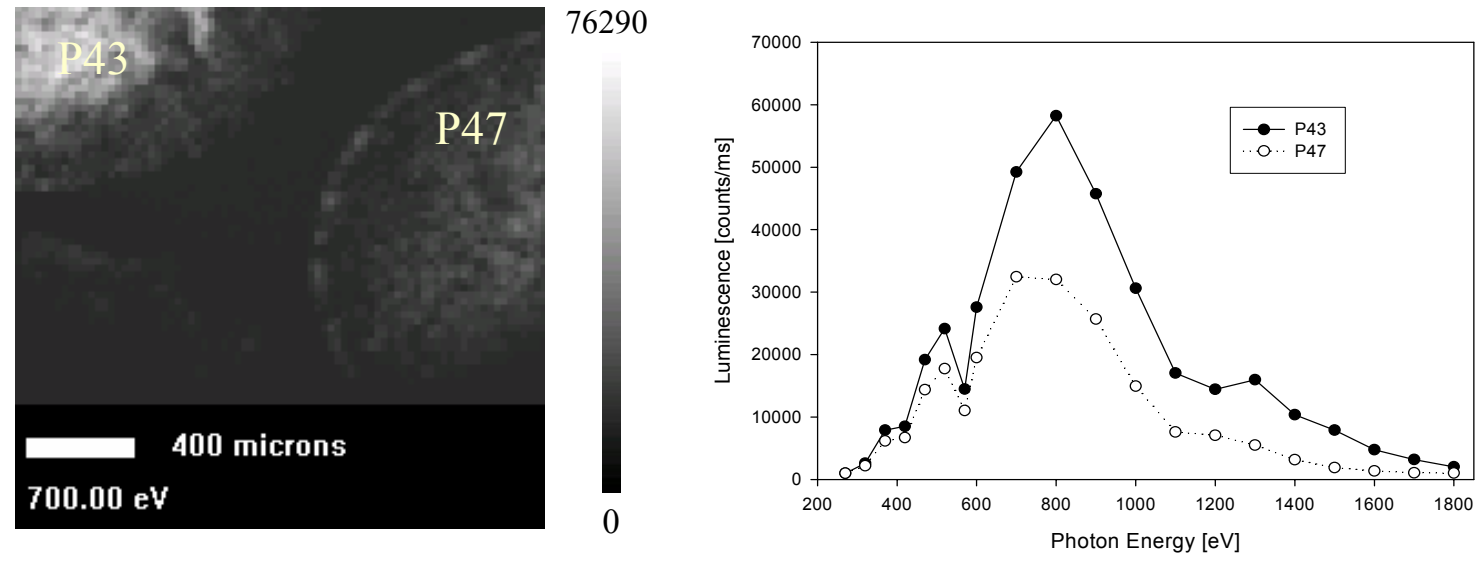

Figure 4. (a) Luminescence image of phosphor powders. (b) Relative luminescence intensity of single grains as function of x-ray photon energy.

Figure 5 shows the $\mathrm{P} 47$ and $\mathrm{P} 43$ phosphor grains in higher magnification. What is characteristic of the powders, is that the luminescence is not homogeneous. It depends on the shape and size of individual grains as well as on how the grains are joined together. On a microscale, it is probably not possible to make a thin phosphor layer with homogeneous sensitivity to soft $\mathrm{x}$-rays.

An interesting observation was that the P47 phosphor lost luminescence intensity with prolonged exposure to xrays. With photons of $640 \mathrm{eV}$ energy and flux of about $5 \times 10^{8} \mathrm{ph} / \mathrm{s}$ in a $40 \mathrm{~nm}$ size spot, the luminescence decreased about $30 \%$ after a $10 \mathrm{~min}$ exposure.

Another important characteristic of the scintillators should be considered when making a choice for a STXM detector - decay time. The ALS STXMs can scan as fast as $50 \mu$ s dwell time per pixel. A scintillator decay time should be of the same scale or shorter. All of the scintillators studied have shorter decay times except the P43 phosphor, which has a decay time of about $1 \mathrm{~ms}$. To determine how much distortion to expect from this, we have compared luminescent images of P43 and P47 phosphor grains recorded at about $1 \mathrm{~ms}$ pixel dwell time to those recorded at much faster scanning speed with $50 \mu \mathrm{s}$ (P43) and $80 \mu \mathrm{s}$ (P47) dwell time (Figure 5). 


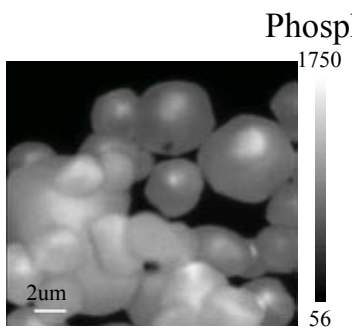

$400 \mathrm{pts}^{2}, 20 \mathrm{um}^{2}, 1.12 \mathrm{~ms}, 640 \mathrm{eV}$

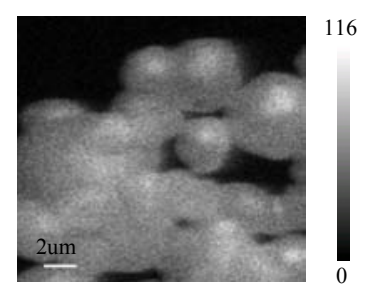

$200 \mathrm{pts}^{2}, 20 \mathrm{um}^{2}, 0.05 \mathrm{~ms}, 640 \mathrm{eV}$

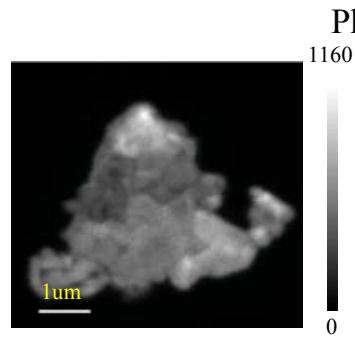

$200 \mathrm{pts}^{2}, 6 \mathrm{um}^{2}, 1.04 \mathrm{~ms}, 640 \mathrm{eV}$
Phosphor P47

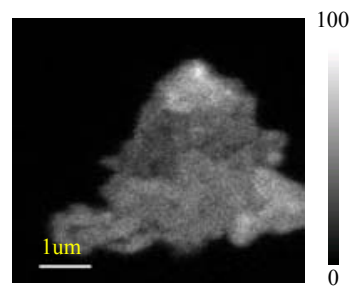

$200 \mathrm{pts}^{2}, 6 \mathrm{um}^{2}, 0.08 \mathrm{~ms}, 640 \mathrm{eV}$

Figure 5. Luminescence images of P43 and P47 phosphor powders recorded at slow and fast scanning speeds. The P43 displays low intensity shadows on the right hand side of individual grains at high scanning speed.

Figure 6 shows scanning profiles of phosphor grains from images shown in Figure 5. Fast scans of the P43 grain exhibit distortions due to slow decay. A "tail" in the profile of grain luminescence is equivalent to the decay time of about $200 \mu$ s.
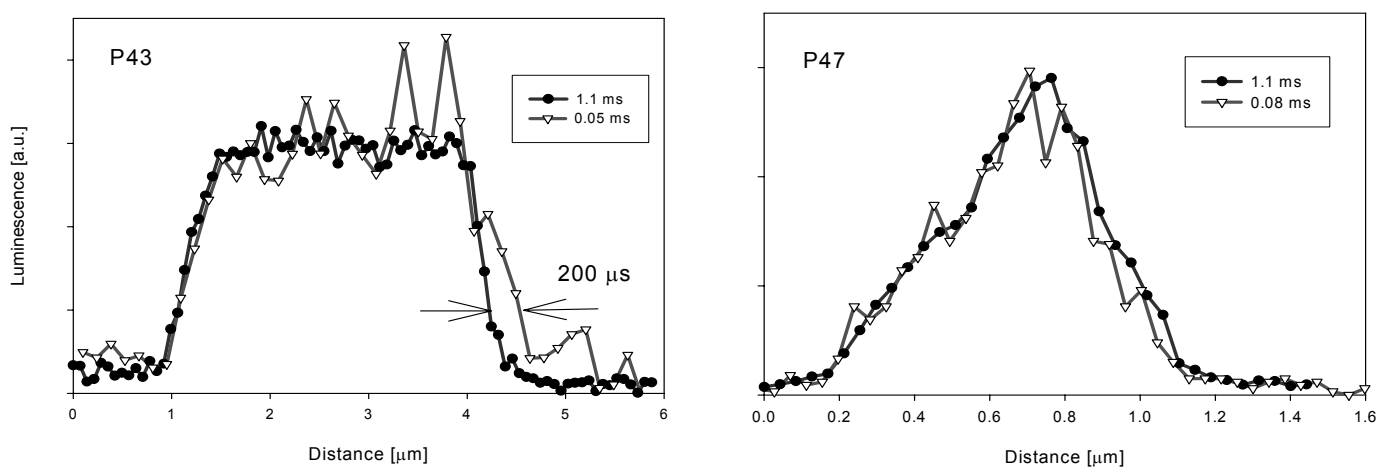

Figure 6. Normalized scanning profiles of $\mathrm{P} 43$ and $\mathrm{P} 47$ phosphor particles from slow and fast scans.

\section{CONCLUSION}

In the scanning transmission x-ray microscope application, the detector efficiency is more important than the homogeneity of its sensitivity. Thus, powder phosphors are a better choice as a scintillator than single crystals. In the case of imaging radiation sensitive samples the P43 phosphor is a preferred choice. When the samples are not so sensitive to radiation damage and there is sufficient photon flux to use very fast scanning speeds, the P47 phosphor should be used.

\section{ACKNOWLEDGMENTS}

The Advanced Light Source and this work are supported by the Director, Office of Science, Office of Basic Energy Sciences, Division of Materials Sciences and the Division of Chemical Sciences, Geosciences, and Biosciences of the U.S. Department of Energy at Lawrence Berkeley National Laboratory under Contract No. DEAC03-76SF00098.

\section{REFERENCES}

[1] A. L. D. Kilcoyne, T. Tyliszczak, W. F. Steele, S. Fakra, P. Hitchcock, K. Franck, E. Anderson, B. Harteneck, E. G. Rightor, G. E. Mitchell, A. P. Hitchcock, L. Yang, T. Warwick, and H. Ade, J. Synchrotron Rad. 10, 125-136 (2003).

[2] "Development of inorganic scintillators", Eijk, C.W.E. van, Nuclear Instruments and Methods in Physics Research A, 392, (1997) $285-290$. 